\title{
O PROCESSO PENAL NA SOCIEDADE DE RISCO: A PERSECUÇÃO PENAL ENTRE OS IDEAIS DE LIBERDADE E SEGURANÇA
}

\begin{abstract}
Resumo: O artigo se propõe a examinar a expansão da intervenção penal no ordenamento jurídico brasileiro e sua relação com o incremento dos riscos inerentes à globalização e à complexidade da sociedade contemporânea. A este efeito, a partir da evolução legislativa brasileira nas últimas duas décadas, pretende-se demonstrar que a expansão da intervenção penal encontra seu fundamento na teoria constitucional dos deveres objetivos de proteção dos direitos fundamentais, impostos ao Estado, apresentando-se as críticas a essa teoria no âmbito do processo penal.
\end{abstract}

André Machado Maya

Palavras-chave: Processo Penal; Sociedade de risco; Expansão; Segurança; Liberdade.

\section{THE CRIMINAL PROCESS IN THE RISK SOCIETY: CRIMINAL PROSECUTION BETWEEN THE IDEALS OF LIBERTY AND SECURITY}

\begin{abstract}
The article proposes to examine the expansion of criminal intervention in the Brazilian legal system and its relationship with the increasing risks inherent to globalization and the complexity of contemporary society. To this end, as a result of the Brazilian legislative evolution in the last two decades, it is intended to demonstrate that the expansion of criminal intervention is based on the constitutional theory of the objective duties of protection of fundamental rights, imposed on the State, presenting the critics to this theory in the criminal procedure.
\end{abstract}

Keywords: Criminal procedure; Risk society; Expansion; Security; Liberty.

\footnotetext{
${ }^{1}$ Doutor em Ciências Criminais pela PUCRS; Mestre em Ciências Criminais pela PUCRS; Especialista em Direito do Estado pela UniRitter e em Ciências Penais pela PUCRS. Professor de Direito Penal e Processo Penal dos cursos de Graduação e Mestrado em Direito da Fundação Escola Superior do Ministério Público do Rio Grande do Sul (FMP). Membro fundador do Instituto Brasileiro de Direito Processual Penal (IBRASPP), com sede na cidade de Porto Alegre, Rio Grande do Sul. Assessor de Desembargador junto ao Tribunal de Justiça do Rio Grande do Sul. E-mail de contato: andremmaya@gmail.com
} 


\section{INTRODUÇÃO}

A expansão do controle punitivo do Estado através do Direito Penal, material e adjetivo, é característica marcante da sociedade contemporânea nas últimas décadas. Tal afirmação é consensual entre os pesquisadores desse âmbito das ciências jurídicas, assim como também o é o fundamento que conduz a essa expansão: a busca por mais segurança diante do surgimento de novos riscos inerentes ao desenvolvimento tecnológico, como também do incremento de outros perigos já conhecidos, mas agora potencializados pela complexidade das relações sociais que marcam a contemporaneidade. Diante desse cenário, o presente ensaio se propõe a examinar os efeitos dessa expansão do controle estatal no âmbito processual penal, notadamente pela via legislativa. O intuito é demarcar os diplomas legislativos que nestes últimos anos implementam novos meios de investigação e produção de prova no âmbito criminal para, então, examinar em que medida se verifica uma efetiva flexibilização de garantias em prol da maior eficiência da persecução penal e, ainda, se tal cenário possui relação com a tendência político-criminal de preeminência da segurança em detrimento das liberdades. A este efeito, a primeira parte do estudo é destinada a contextualizar o cenário de expansão do Direito Penal material e processual no âmbito da chamada sociedade de risco, delineando seus fundamentos. Na segunda parte do ensaio, pretende-se mapear a atividade político-legislativa em matéria processual penal, para então, ao final, propor um exame crítico do atual estado da arte em matéria de persecução penal no ordenamento jurídico brasileiro.

\section{A EXPANSÃO DO CONTROLE PENAL ENTRE OS IDEAIS DE SEGURANÇA E LIBERDADE}

Observados os objetivos a que se propõe o presente ensaio, e ainda que sem a pretensão de aprofundar um tema sobre o qual há várias obras de relevo no âmbito da sociologia e da filosofia (BECK, 1998; GIDDENS, 1991; LUHMANN, 1999), afigura-se fundamental destacar, como ponto de partida, que o problema objeto deste estudo situa-se no âmbito da denominada sociedade de risco, assim consideradas as sociedades contemporâneas inseridas no contexto da globalização econômica, da integração supranacional e do constante avanço tecnológico, identificadas pela lógica de produção e distribuição do risco (PÉREZ CEPEDA, 2007, p. 314).

Não há consenso ou mesmo determinação acerca do significado de risco no âmbito das ciências sociais. Ainda assim, tomando como base o debate inaugurado por Ulrick Beck na

Rev. de Direito Penal, Processo Penal e Constituição | e-ISSN: 2526-0200 | Brasília | v. 3 | n. 1 | p. 97 - 117 | Jan/Jun. 2017 


\section{O PROCESSO PENAL NA SOCIEDADE DE RISCO: A PERSECUÇÃO PENAL ENTRE OS IDEAIS DE LIBERDADE E SEGURANÇA}

sua obra Sociedad del riesgo: hacia una nueva modernidad, depreende-se que tal questão surge como fator característico da transição entre o que o sociólogo alemão denomina de primeira e segunda modernidades, marcada pelo surgimento de um novo modelo de capitalismo, fortemente influenciado pela globalização, pelo individualismo excessivo, pela escassez de recursos ecológicos e pelas turbulências no âmbito dos mercados financeiros. Entre rupturas e contradições surge uma segunda modernidade, uma modernidade reflexiva, na medida em que relacionada à instabilidade e à imprevisibilidade proporcionada pela constante evolução do conhecimento (BECK, 1998). Daí a utilização da expressão risco, a identificar a variável de incerteza resultante da evolução do conhecimento, que impede a programação exata do futuro.

$\mathrm{Na}$ dinâmica característica dessa modernidade denominada por Antonhy Giddens como tardia (1991), a concepção de risco externo que marcou a sociedade industrial clássica, em alusão aos perigos decorrente da natureza, é contraposta pela ideia de risco fabricado pela intervenção humana, decorrente do desenvolvimento científico e tecnológico, o que autoriza Campione a afirmar que "a intervenção controlada do homem na sociedade e na natureza não produziu a certeza que o projeto da ilustração esperava do avanço do conhecimento" (2003, p. 15). A toda evidência, a pretensão de controle do futuro pelo homem, através da ciência e da tecnologia, potencializou os riscos à própria existência humana, na exata medida das incertezas inerentes ao avanço do conhecimento.

É neste cenário que se estabelecem as premissas de uma política criminal orientada à segurança em detrimento de liberdades individuais, notadamente pautada (I) no surgimento de novos riscos, (II) na dificuldade de atribuição de responsabilidade penal a pessoas físicas e jurídicas, no que se refere a esses riscos, e (III) na sensação de insegurança disseminada em especial pela atuação da mídia no exercício desregulado da liberdade de imprensa, o que resulta potencializado pela dificuldade de compreensão do cidadão leigo acerca dos limites postos ao exercício do poder punitivo estatal no âmbito dos Estados Democráticos de Direito (DIEZ RIPOLLÉS, 2005, p. 05).

Neste contexto, a expansão do controle penal tem como pilares estruturantes a criação de novos bens jurídico-penais, a ampliação dos espaços de risco jurídico penalmente relevante, a flexibilização das regras de imputação e a relativização dos princípios políticos criminais de garantia (SILVA SÁNCHEZ, 2006, p. 20), pondo em destaque uma opção por mais Direito Penal em termos quantitativos e qualitativos (D’ÁVILA, 2012). A concepção do Direito Penal pautado no princípio de intervenção mínima, essência do denominado modelo garantista, cede

Rev. de Direito Penal, Processo Penal e Constituição | e-ISSN: 2526-0200 | Brasília | v. 3 | n. 1 | p. 97 - 117 | Jan/Jun. 2017 
em face de uma "verdadeira demanda social de mais proteção" que pauta a sociedade nas últimas décadas (SILVA SÁNCHEZ, 2006, p. 22).

O Direito Penal que dessa receita resulta, adverte Díez Ripollés (2005, p. 05) é marcado pelo incremento da tipificação de condutas que atentam contra novos bens jurídicos de natureza coletiva, pelo predomínio dos tipos de perigo abstrato em detrimento das figuras delitivas de resultado, dada a necessidade de antecipação da intervenção penal como forma de lidar com o perigo e evitar o dano, e por significativas mudanças no sistema de atribuição de responsabilidade, como é o caso da flexibilização de garantias materiais e processuais, a partir do que são admitidas certas restrições à segurança jurídica em prol da maior efetividade da intervenção penal, do que é exemplo a crescente preferência por tipos penais em branco, a adesão irrefletida à ideologia da tolerância zero, a proliferação de leis de emergência e o aumento de leis de tonalidade securitária (FARIA COSTA, 2010, p. 60).

Especificamente no que importa ao objeto em estudo, a conformação de novas realidades até pouco tempo desconhecidas, como é o caso dos meios de comunicação que surgem e são aperfeiçoados de maneira constante e acelerada pela evolução tecnológica, e também a ordem econômica contemporânea, em nada semelhante ao que se conhecia há até pouco tempo, conformam os denominados novos riscos e impõem naturalmente a necessidade de tutela estatal. Trata-se de riscos tecnológicos, os quais se diferem dos riscos não tecnológicos inerentes à denominada criminalidade tradicional, de rua, e assim impõem ao Estado um novo padrão de proteção, distinto do clássico paradigma de tutela dos bens jurídicos primários, característico do Direito Penal liberal.

A percepção desses novos perigos é influenciada pela incerteza inerente ao desconhecido e à velocidade do avanço tecnológico. O custo da tecnologia, neste aspecto, afeta a estabilidade - pressuposto da segurança - e, consequentemente, gera uma sensação naturalmente subjetiva - de insegurança, a qual torna instáveis e mais pueris as relações sociais. Na abalizada doutrina de Silva Sánchez (2006, p. 28 e seg.), a incerteza inerente ao emprego de novas técnicas e à comercialização de produtos e utilização de tecnologias cujos efeitos se desconhece institucionaliza a insegurança. Em uma aproximação subjetiva, trata-se da ansiedade resultante da impossibilidade de se dominar o curso dos acontecimentos, como já apontado por Beck (1998) e Giddens (1991). E como bem pontuado por Silva Sánchez, essa dimensão subjetiva assume, sem dúvidas, proporções superiores à dimensão objetiva, do risco efetivo, e inequivocamente surte efeitos na política criminal dos Estados contemporâneos, 


\section{O PROCESSO PENAL NA SOCIEDADE DE RISCO: A PERSECUÇÃO PENAL ENTRE OS IDEAIS DE LIBERDADE E SEGURANÇA}

influenciando diretamente na restrição dos riscos permitidos e na ampliação dos riscos penalmente dignos de tutela penal.

O moderno Direito Penal, então, se transforma, abandonando sua missão primeira de evitar lesões a bens jurídicos fundamentais e assumindo a tarefa de assegurar a previsibilidade de existência da sociedade. Assim o faz ao dar primazia à técnica dos tipos de perigo abstrato, antecipando a reação frente à insegurança social que resulta da complexidade, das inovações e das mudanças estruturais nos âmbitos econômico e tecnológico. A dimensão simbólica do acautelamento do futuro e da existência humana está na antecipação da intervenção punitiva. Como consequência, a prevenção assume posição de protagonismo na política de segurança do Estado, a ponto de se falar em uma cultura preventiva relacionada ao gerenciamento dos riscos permitidos e não permitidos. A pauta da complexa sociedade contemporânea é prevenir esses riscos, e para tanto a intervenção penal, no âmbito material, é antecipada ao momento anterior à lesão, enquanto no âmbito processual tem como principal característica a supressão de garantias em prol de uma presumida eficácia (PÉREZ CEPEDA, 2007, p. 321; FARIA COSTA, 2010, p. 63).

Ao objeto do presente ensaio importa especificamente o aspecto processual da intervenção penal. A prevenção, enquanto gerenciamento de riscos, pressupõe controle, e a eficácia do controle é proporcionalmente maior quanto mais alargado for o âmbito do que possa ser controlado. Disso resulta que, com o intuito de maximizar a segurança através da prevenção, acentua-se a tendência de relativização das garantias individuais fundamentais, seja operando restrições diretamente pela via legislativa, seja flexibilizando regras processuais de garantia, notadamente as relacionadas às nulidades processuais. No conflito entre liberdade e segurança, aquela cede frente a esta, em uma opção a toda evidência influenciada pelos riscos e pelos medos que se apresentam, e legitimada pela ideia de que a limitação da liberdade se propõe a salvar a própria liberdade (FARIA COSTA, 2010, p. 58).

No âmbito dos riscos tecnológicos, assim considerados todos aqueles relacionados com o avanço das tecnologias disponíveis à comunicação e a transações econômicas, a eficácia da prevenção e a segurança das relações passam diretamente pela tendência de restrição dos limites de sigilo inerente às garantias de intimidade e privacidade. Exemplo disso são as obrigações de conservação de dados impostas aos agentes financeiros e às concessionárias privadas operadoras de serviços de comunicação, bem como a ampliação das possibilidades de acesso a esses dados por parte das autoridades responsáveis pela persecução penal. De outro

Rev. de Direito Penal, Processo Penal e Constituição | e-ISSN: 2526-0200 | Brasília | v. 3 | n. 1 | p. 97 - 117 | Jan/Jun. 2017 
lado, no âmbito dos riscos não tecnológicos, mas decorrentes indiretamente destes, como é o caso dos crimes praticados por organizações criminosas e relacionados à lavagem de capitais, corrupção e tráfico de drogas e pessoas, a eficácia da segurança passa pela implementação de novos meios de investigação e produção de prova, do que são exemplos as técnicas de infiltração policial, ação controlada e colaboração premiada, dentre outras. O presente ensaio tem por objetivo uma aproximação a esse cenário legislativo no âmbito do ordenamento jurídico brasileiro.

\section{A EVOLUÇÃO LEGISLATIVA BRASILEIRA EM MATÉRIA DE PERSECUÇÃO PENAL}

Os impactos do cenário acima delineado no âmbito do direito processual penal são destacados pela doutrina contemporânea especializada, notadamente no tocante à aceleração da resposta estatal pela via da antecipação da tutela penal, o que é facilmente identificado pelo incremento da utilização da prisão preventiva, por exemplo. Há, porém, casos em que a intervenção punitiva estatal foge aos padrões tradicionais do sistema repressivo (no que se incluem as medidas cautelares), materializando-se por vias que constituem "um subsistema de derrogação dos cânones empregados na normalidade", ao que se entabulou denominar de processo penal de emergência (CHOUKR, 2002, p. 06; FARIA COSTA, 2010, p. 60).

Neste cenário, seja pela via jurisdicional, seja pela via legislativa, medidas restritivas de liberdades individuais assumem status de normalidade no âmbito do sistema penal, como é o caso das exceções à inadmissibilidade constitucional de provas ilícitas, da ampliação das hipóteses de prisões cautelares e da resistência à utilização das medidas alternativas ao encarceramento preventivo, da restrição do âmbito de eficácia do habeas corpus, da ampliação dos poderes de iniciativa do juiz inclusive ao âmbito pré-processual, da admissibilidade dos poderes gerais de cautela e da utilização irrestrita de meios atípicos de prova no curso do processo penal. Especificamente no plano legislativo, é perceptível a tendência de flexibilização de garantias individuais inerente à regulamentação de técnicas investigativas que buscam atribuir maior eficiência na prevenção de ilícitos praticados por organizações criminosas e aos demais relacionadas à lavagem de capitais, seja criando novas metodologias de investigação e produção de prova, seja implementando deveres de conservação de dados cadastrais e de comunicação, bem como disciplinando o acesso a esses dados por parte das autoridades responsáveis pela persecução penal, por vezes independentemente de autorização judicial.

Rev. de Direito Penal, Processo Penal e Constituição | e-ISSN: 2526-0200 | Brasília | v. 3 | n. 1 | p. 97 - 117 | Jan/Jun. 2017 


\section{O PROCESSO PENAL NA SOCIEDADE DE RISCO: A PERSECUÇÃO PENAL ENTRE OS IDEAIS DE LIBERDADE E SEGURANÇA}

No âmbito do ordenamento jurídico brasileiro, essa tendência se apresentou inicialmente por meio da já revogada Lei 9.034/95, que dispunha sobre a utilização de meios operacionais para a prevenção e a repressão de ações praticadas por organizações criminosas. Antes mesmo da Convenção das Nações Unidas contra o crime organizado transnacional, ${ }^{2}$ a legislação brasileira já autorizava, em qualquer fase da persecução criminal, a ação controlada; o acesso a dados, documentos e informações fiscais, bancárias, financeiras e eleitorais; a captação e a interceptação ambiental de sinais eletromagnéticos, óticos ou acústicos, bem como seu registro e análise, mediante autorização judicial; a infiltração policial em tarefas de investigação, também mediante autorização judicial; e a colaboração premiada para agentes que levassem ao esclarecimento das infrações e sua autoria. Ainda, e sob o argumento da necessidade de preservação do sigilo fiscal, bancário e eleitoral, previa a mencionada legislação, em seu artigo $3^{\circ}$, a hipótese de prática dos atos de investigação pessoalmente pelo magistrado, o que acabou declarado inconstitucional quando do julgamento da ADI 1570-2, pelo Supremo Tribunal Federal, bem como vedava expressamente a concessão de liberdade provisória e a possibilidade de recorrer em liberdade, além de determinar o cumprimento de pena em regime inicial fechado e a identificação criminal das pessoas envolvidas com esses delitos, independentemente da identificação civil.

A ausência de um conceito preciso de organização criminosa, de um lado, e a falta de especificação acerca dos procedimentos de investigação disciplinados, de outro, restringiram a efetividade da Lei 9.034/95, que na prática não obteve aplicabilidade plena e acabou revogada pela Lei 12.850/13. Não obstante isso, é sintomático que antes mesmo da assinatura da Convenção de Palermo já houvesse no Brasil previsão legislativa de medidas investigatórias como infiltração de agentes, ação controlada e interceptação de sinais eletromagnéticos, óticos e acústicos, bem como de prêmio ao agente que colaborasse no esclarecimento de infrações perpetradas por organizações criminosas. Tanto é indicativo concreto de que o tema da prevenção e da repressão à criminalidade organizada já consta da pauta político-criminal brasileira há longa data.

Foi, no entanto, após a virada do milênio que a mencionada tendência de flexibilização de garantias em prol da maior eficiência da persecução penal se apresentou de maneira mais sintomática. Em 2006, com o advento da Lei 11.343, que instituiu o sistema nacional de

\footnotetext{
${ }^{2}$ Assinada em Nova Iorque, em 15.12.2000.
} 
políticas públicas sobre drogas e estabeleceu normas para a repressão à produção não autorizada e ao tráfico ilícito de drogas, alguns dos meios de investigação previstos pela Lei 9.034/95 tornaram a ser tipificados. É o caso da infiltração de agentes policiais em tarefas de investigação e da não atuação policial sobre portadores de drogas, quando conhecido o itinerário e mediante autorização judicial, como forma de identificação e responsabilização de um maior número de pessoas envolvidas com a prática delituosa. Ainda, foi também prevista a colaboração premiada, bem como estabelecida a vedação da liberdade provisória, a inafiançabilidade, a insuscetibilidade de graça, anistia, indulto e a vedação da conversão de penas restritivas de direitos, bem como a impossibilidade de que o condenado recorresse em liberdade, exceto nos casos em que primário e de bons antecedentes.

O rigor da Lei 11.343/06 no tratamento dispensado ao acusado da prática de tráfico de drogas foi paulatinamente amenizado pela jurisprudência, notadamente do Supremo Tribunal Federal, que declarou a inconstitucionalidade da vedação da liberdade provisória, da conversão da pena em restritiva de direitos, bem como da proibição absoluta do direito de recorrer em liberdade. Até mesmo a hediondez do tráfico na forma privilegiada restou afastada pelo entendimento da Suprema Corte, do que resultou a possibilidade de indulto, nesses casos específicos. Não obstante isso, afigura-se inequívoco o recrudescimento da política criminal em relação à repressão aos crimes relacionados ao tráfico de substâncias entorpecentes, em termos de persecução penal. A expressa autorização para infiltração policial e para não atuação em determinados casos seguiu a linha inaugurada pela Lei 9.034/95, a evidenciar a preocupação do legislador com a eficiência da repressão penal.

Seguindo esta tônica, os anos de 2012 e 2013 foram sintomáticos a evidenciar essa tendência que se anunciava desde 1995. As Leis 12.654/12, que estabeleceu a coleta de perfis genéticos para fins de identificação criminal; 12.683/12, editada com o intuito de tornar mais eficiente a persecução penal dos crimes de lavagem de dinheiro; 12.694/12, que instituiu o julgamento por órgãos colegiados de primeiro grau de jurisdição, para os delitos envolvendo organizações criminosas; e 12.850/13, que definiu organização criminosa e estabeleceu meios de investigação e de obtenção de prova, incorporaram ao ordenamento jurídico brasileiro uma série de medidas restritivas de garantias em prol da eficiência no combate à criminalidade, seguindo a tendência securitária do sistema penal contemporâneo.

A Lei 12.654/12 alterou dispositivos da Lei de Execuções Penais e da Lei 12.037/09, que dispõe acerca da identificação criminal do civilmente identificado. Neste último caso, estabeleceu que a identificação criminal poderá incluir a coleta de material biológico para 


\section{O PROCESSO PENAL NA SOCIEDADE DE RISCO: A PERSECUÇÃO PENAL ENTRE OS \\ IDEAIS DE LIBERDADE E SEGURANÇA}

obtenção do perfil genético, quando aquela for essencial à investigação policial, segundo decisão da autoridade jurisdicional competente, de ofício ou mediante representação da autoridade policial, do Ministério Público ou da defesa. Já por meio da alteração da LEP, fez constar a obrigatoriedade de identificação do perfil genético, mediante extração de DNA, de todos os condenados por crimes hediondos ou praticados dolosamente, com violência de natureza grave contra a pessoa.

A questão posta de relevo aqui guarda relação com as garantias de intimidade e de não identificação criminal, do civilmente identificado. Não paira dúvidas quanto à possibilidade de restrição dessas garantias fundamentais, notadamente desta última, diante da explícita previsão inserida na parte final do artigo 5 , LVIII, da Constituição Federal de 1988. ${ }^{3}$ Ainda assim, a toda evidência a previsão legislativa representa uma restrição orientada por política criminal que, inequivocamente, amplia o controle penal.

Neste ponto, a crítica centra-se na amplitude da restrição, evidenciada pela ausência de limites em relação a quem está sujeito à identificação criminal por perfil genético. Basta observar que a lei não estabelece previa e abstratamente que tipos de delitos autorizam essa identificação, do que decorre que tal pode ser adotada em qualquer investigação criminal, independentemente da gravidade do delito objeto da persecução, bastando a justificativa acerca da sua essencialidade, o que tampouco foi objeto de específica regulamentação do legislador. Naturalmente que essa essencialidade pressupõe a proporcionalidade da medida em relação ao objeto da investigação, mas a ausência de especificação a esse respeito enseja uma lacuna legal que propicia campo fértil a possíveis abusos. Semelhante crítica aplica-se também à identificação de perfis genéticos de condenados por crimes hediondos ou praticados com violência contra a pessoa, na medida em que a legislação também não estabeleceu critérios de adequação, necessidade e proporcionalidade para essa medida, deixando tal possibilidade em aberto, independentemente da natureza do delito objeto da condenação.

Ainda em 2012, a Lei 12.683 foi promulgada com o intuito de tornar mais eficiente a persecução penal dos crimes de lavagem de dinheiro. A este efeito estabeleceu obrigações de compliance e de comunicação de operações financeiras suspeitas ao COAF, e instituiu, no artigo 17-B, a possibilidade de acesso da autoridade policial e do Ministério Público aos dados cadastrais do investigado, mantidos pela Justiça Eleitoral, pelas empresas telefônicas, pelas

\footnotetext{
${ }^{3}$ A legitimidade dessa restrição é objeto do RE 973.837/MG, em trâmite perante o Supremo Tribunal Federal.
} 
instituições financeiras, pelos provedores de internet e pelas administradoras de cartões de crédito, independentemente de autorização judicial.

Especificamente em matéria de investigação criminal, o acesso a dados independentemente de autorização judicial, ainda que exclusivamente cadastrais, representa evidente flexibilização da garantia da intimidade, notadamente se considerado o entendimento até então consolidado no âmbito do Superior Tribunal de Justiça, no sentido de que mesmo esse tipo de acesso dependia de autorização judicial. ${ }^{4}$

No âmbito da repressão à criminalidade organizada, a complementar a Lei 9.034/95, também em 2012 foi promulgada a Lei 12.694, que inaugurou no ordenamento jurídico brasileiro a possibilidade de julgamento colegiado em primeiro grau de jurisdição, nos casos de persecução penal de crimes praticados por organizações criminosas.

Pautada em específica casuística, a mencionada legislação, para além de definir um conceito de organização criminosa em seu artigo $2^{\circ}$, suprindo lacuna da Lei 9.034/95, autoriza a formação excepcional e discricionária de um juizado colegiado para a prática de quaisquer atos processuais referentes a processos ou procedimentos que tenham por objeto crimes praticados por organizações criminosas (art. $1^{\circ}$, caput), quando constatada a existência de risco a sua integridade física $\left(\S 1^{\circ}\right)$. Ademais, permite a reunião sigilosa de seus integrantes, quando a publicidade puder importar prejuízo à eficácia do ato $\left(\S 4^{\circ}\right)$, e a publicação apenas parcial de suas decisões, pois vedada a referência a voto divergente de qualquer dos seus membros $\left(\S 6^{\circ}\right)$.

A toda evidência a legislação em comento estabelece restrições às garantias constitucionais do juiz natural e da publicidade dos atos do Poder Judiciário. Novamente aqui a questão não passa por sustentar a impossibilidade de restrições estabelecidas por lei a essas cláusulas fundamentais, mas por examinar o âmbito dessas restrições, bem como a adequação e a proporcionalidade das mesmas, no contexto de um processo penal compatível com os padrões democráticos.

Já no ano de 2013, mas ainda no tocante ao tema da criminalidade organizada, sobreveio a promulgação da Lei 12.850, que estabeleceu novo conceito de organização criminosa, tipificou penalmente essa a conduta de integrar organização criminosa e dispôs sobre meios específicos de investigação e obtenção de prova. Aos objetivos do presente estudo, interessa aqui essa última parte.

\footnotetext{
${ }^{4}$ Neste sentido: RHC 8.493/SP, Rel. Ministro LUIZ VICENTE CERNICCHIARO, SEXTA TURMA, julgado em 20/05/1999, DJ 02/08/1999, p. 224; RHC 5.065/MG, Rel. Ministro EDSON VIDIGAL, QUINTA TURMA, julgado em 19/03/1996, DJ 29/09/1997, p. 48228.
}

Rev. de Direito Penal, Processo Penal e Constituição | e-ISSN: 2526-0200 | Brasília | v. 3 | n. 1 | p. 97 - 117 | Jan/Jun. 2017 


\section{O PROCESSO PENAL NA SOCIEDADE DE RISCO: A PERSECUÇÃO PENAL ENTRE OS \\ IDEAIS DE LIBERDADE E SEGURANÇA}

Ao contrário do que se verificara na Lei 9.034/95 e na Lei 11.343/06, que previram a possibilidade de adoção de novas metodologias de investigação, porém sem especificar os respectivos procedimentos, a Lei 12.850/13 disciplinou de maneira detalhada esses novos meios de investigação e produção de prova. Em seu artigo $3^{\circ}$, expressamente autorizou a colaboração premiada; a captação ambiental de sinais eletromagnéticos, ópticos e acústicos; a ação controlada; o acesso a registro de ligações telefônicas e telemáticas, a dados cadastrais constantes de bancos de dados públicos ou privados e a informações eleitorais ou comerciais; a interceptação das comunicações telefônicas e telemáticas; o afastamento dos sigilos financeiro, bancário e fiscal; a infiltração de policiais em atividades de investigação; e a cooperação entre instituições e órgãos federais, distritais, estaduais e municipais na busca de provas e informações de interesse da investigação ou da instrução criminal.

A colaboração premiada, assim como a infiltração policial, a ação controlada, e o acesso a dados públicos e privados foram disciplinados nos artigos seguintes da mencionada lei, com previsões específicas dos seus pressupostos de admissibilidade e requisitos de validade, bem como do procedimento a ser adotado pela autoridade policial ou pelo Ministério Público.

A infiltração policial é admitida no âmbito de investigação criminal específica de fatos praticados por organizações criminosas, mediante circunstanciada e motivada autorização judicial, e quando a prova não puder ser produzida por outros meios disponíveis (artigo 10, caput e $\S 2^{\circ}$ ). A medida pode ser adotada pelo período máximo de seis meses $\left(\S 3^{\circ}\right)$, mas com possibilidade indefinida de renovações, desde que comprovada sua necessidade, sendo impositiva a apresentação de relatório circunstanciado pela autoridade policial, o que pode ser requisitado pelo Ministério Público a qualquer tempo $\left(\$ \S 4^{\circ}\right.$ e $\left.5^{\circ}\right)$. Ainda, no artigo 11 consta a expressa necessidade de o Ministério Público ou o Delegado de Polícia demonstrarem a necessidade da medida, no pedido formulado, assim como o alcance das tarefas a serem executadas, de determinar o local da infiltração e de identificar os suspeitos pelo nome ou apelido. O procedimento é sigiloso (artigo 12) e o agente infiltrado deve observar, na execução das tarefas, a proporcionalidade em relação ao objetivo da investigação, respondendo pelos excessos praticados (artigo 13), salvo no caso de prática de crimes, quando inexigível conduta diversa ( $\$$ único).

Na mesma linha, a ação controlada é definida como o retardamento da intervenção policial ou administrativa em relação à ação delituosa perpetrada por organização criminosa, mediante a condição de que a autoridade policial mantenha sob observação e acompanhamento

Rev. de Direito Penal, Processo Penal e Constituição | e-ISSN: 2526-0200 | Brasília | v. 3 | n. 1 | p. 97 - 117 | Jan/Jun. 2017 
a conduta, e com o objetivo de que com isso a intervenção se concretize em momento mais eficaz à formação de provas e obtenção de informações (artigo 8). Também nesse caso a medida é sigilosa $\left(\S 2^{\circ}\right)$ e deve ser comunicada previamente ao juiz competente, a quem compete estabelecer os limites da não atuação policial $\left(\S 1^{\circ}\right)$.

A colaboração premiada, a seu turno, está regulada nos artigos $4^{\circ}$ a $7^{\circ}$ da mencionada legislação, e prevê a possibilidade de concessão de perdão judicial, redução da pena em até 2/3 ou substituição por restritivas de direitos, o não oferecimento de denúncia e a redução da pena imposta na sentença em até metade, ou a progressão de regime prisional ainda que ausentes os requisitos objetivos para tanto, a quem colaborar efetiva e voluntariamente com a investigação criminal e com o processo, e desde que a colaboração alcance um dos objetivos listados nos incisos do artigo $4^{\circ}$ da Lei, quais sejam: identificação de coautores e partícipes e das infrações penais por eles praticadas; revelação da estrutura hierárquica e da divisão de tarefas da organização criminosa; recuperação parcial ou total do produto ou do proveito das infrações penais; e localização de eventual vítima com sua integridade física preservada. Há ainda expressa previsão de que o juiz não poderá participar das negociações entre as partes, de modo a garantir sua imparcialidade no momento da homologação do acordado, bem como de possibilidade de suspensão do prazo para oferecimento da denúncia por até seis meses, prorrogáveis por igual período, a fim de que sejam cumpridas as medidas de colaboração, caso em que também fica suspenso o prazo prescricional. Ademais, há expressa previsão de possibilidade de oitiva do colaborador em juízo, bem como de que o mesmo, ao efetuar o acordo, renunciará ao direito ao silêncio, estando sujeito ao compromisso legal de dizer a verdade.

Por último, entre os artigos 15 e 17 da Lei 12.850/13 estão reguladas as medidas de acesso a dados públicos e privados. No artigo 15 consta a possibilidade acesso pela autoridade policial e pelo Ministério Público, independentemente de autorização judicial, aos dados cadastrais do investigado que informem a sua qualificação pessoal, filiação e endereço, mantidos pela Justiça Eleitoral, pelas empresas telefônicas, instituições financeiras, provedores de internet e administradoras de cartões de crédito. O artigo 16, a seu turno, estabelece a obrigatoriedade de as empresas de transporte conservarem os registros de reservas e de viagens efetuados pelos seus clientes pelo prazo de cinco anos, bem como o dever de possibilitar acesso direto e permanente do juiz, do Ministério Público e do delegado de polícia a esses dados. E o artigo 17 estabelece, às concessionárias de telefonia fixa ou móvel, a obrigação de conservação dos registros de identificação dos números dos terminais telefônicos de origem e destino de

Rev. de Direito Penal, Processo Penal e Constituição | e-ISSN: 2526-0200 | Brasília | v. 3 | n. 1 | p. 97 - 117 | Jan/Jun. 2017 


\section{O PROCESSO PENAL NA SOCIEDADE DE RISCO: A PERSECUÇÃO PENAL ENTRE OS IDEAIS DE LIBERDADE E SEGURANÇA}

quaisquer comunicações telefônicas, também pelo prazo de cinco anos, os quais devem ficar à disposição do Ministério Público e da autoridade policial.

Como visto, a Lei 12.850/13 representa um marco na repressão aos atos delituosos praticados por organizações criminosas no Brasil. Passadas quase duas décadas da promulgação da Lei 9.034/95, agora expressamente revogada, a novel legislação supriu lacunas que na prática inviabilizavam a plena efetividade das medidas de investigação e obtenção de prova já tipificadas no ordenamento jurídico. Além disso, inovou ao estabelecer deveres gerais de conservação de dados públicos e privados, bem como ao possibilitar o acesso aos mesmos pelas autoridades responsáveis pela persecução penal, em alguns casos afastando inclusive a necessidade de prévia autorização judicial.

Nesta esteira, em 2014 foi promulgado o denominado marco civil da internet, através da Lei 12.965, regulamentada no ano de 2016 pelo Decreto $\mathrm{n}^{\circ}$ 8.771. Por este diploma legislativo são destacos como princípios que regem a disciplina normativa do uso da internet a proteção da privacidade e a proteção dos dados pessoais, na forma da lei. Ainda, destaca como direitos dos usuários da internet a inviolabilidade da intimidade e da vida privada, a inviolabilidade e sigilo do fluxo de suas comunicações, ressalvado acesso autorizado judicialmente, a inviolabilidade e sigilo das comunicações privadas armazenadas, também ressalvada a possibilidade de acesso mediante autorização judicial, bem como o não fornecimento a terceiros de dados pessoais do usuário, aqui incluídos os registros de conexão, e a obtenção completa de informações sobre coleta, uso, armazenamento, tratamento e proteção dos dados pessoais. Ainda, é direito do usuário a exclusão definitiva dos dados pessoais que tiver fornecido durante aplicação de internet, ao término da relação entre as partes.

Para além disso, na seção II da mencionada legislação há detalhada previsão de proteção aos registros, aos dados pessoais e às comunicações privadas entabuladas por meios eletrônicos. Consta, no artigo 10, que a conservação e a disponibilização dos registros de conexão e acesso à internet, assim como os dados pessoais e o conteúdo dessas comunicações privadas devem observar a preservação da intimidade, da vida privada, da honra e da imagem, bem como que os provedores somente estarão obrigados a disponibilizar esses registros mediante ordem judicial. A única ressalva, constante do parágrafo $3^{\circ}$ do artigo 10 , refere que o acesso aos dados cadastrais “que informem qualificação pessoal, filiação e endereço", pelas autoridades administrativas e na forma da lei, não configura violação às garantias da intimidade, da vida privada, da honra e da imagem. No artigo 13, consta que os dados

Rev. de Direito Penal, Processo Penal e Constituição | e-ISSN: 2526-0200 | Brasília | v. 3 | n. 1 | p. 97 - 117 | Jan/Jun. 2017 
relacionados aos registros de conexão devem ser conservados pelos provedores sob sigilo, em ambiente controlado e de segurança, pelo prazo de um ano, e que sua disponibilização deverá ser precedida de autorização judicial. No artigo 15, por derradeiro, consta que os registros de acesso a aplicações de internet devem ser mantidos pelo prazo de seis meses, e que sua disponibilização também pressupõe autorização judicial prévia.

No último ano, enfim, duas legislações merecem destaque por seguir a mesma tônica ora destacada. A Lei 13.344/16, inicialmente, veio regular a prevenção e a repressão ao tráfico interno e internacional de pessoas, estabelecendo medidas processuais específicas a essa finalidade. Dentre estas, destacam-se a possibilidade de acesso do Ministério Público e da autoridade policial aos dados e informações cadastrais da vítima ou de suspeitos, registrados por órgãos públicos ou empresas da iniciativa privada, e a obrigatoriedade de as empresas prestadoras de serviços de telecomunicações e/ou telemática, mediante autorização judicial, disponibilizarem os meios técnicos adequados - sinais, informações e outros - que permitam a localização da vítima ou dos suspeitos do delito em execução, pelo prazo máximo de trinta dias.

$\mathrm{Na}$ mesma linha, a Lei 13.441/17 veio regular a infiltração de agentes de polícia na internet, com o específico objetivo de investigar crimes contra a dignidade sexual de criança ou adolescente, incorporando modificações ao Estatuto da Criança e do Adolescente (Lei $8.069 / 90)$.

A mencionada legislação inicia especificando os crimes em cuja investigação será possível a infiltração de agentes policiais no ambiente virtual da internet, ${ }^{5}$ e delimitando as regras para a prática desse meio de investigação, dentre as quais: a imprescindibilidade de prévia autorização judicial, na qual devem ser estabelecidos os limites da infiltração para obtenção de prova; a necessidade de prévio requerimento do Ministério Público ou de representação da autoridade policial, as quais devem demonstrar a necessidade da medida, o alcance das tarefas dos policiais, os nomes ou apelidos das pessoas investigadas e, quando possível, os dados de conexão ou cadastrais que permitam identificar essas pessoas; e o prazo máximo de noventa dias para execução das tarefas, possibilitadas eventuais renovações quando demonstrada essa necessidade e observado o limite de setecentos e vinte dias. Ainda, consta expressa previsão no sentido de que a infiltração, que sempre será sigilosa, não será admitida

\footnotetext{
${ }^{5}$ Conforme artigo $1^{\circ}$ da Lei 13.344/17, tal prática é possível na investigação dos crimes tipificados nos artigos 240, 241, 214-A, 241-B, 241-C e 241-D da Lei 8.069/90, e nos artigos 154-A, 217-A, 218, 218-A e 218-B, do Código Penal.
}

Rev. de Direito Penal, Processo Penal e Constituição | e-ISSN: 2526-0200 | Brasília | v. 3 | n. 1 | p. 97 - 117 | Jan/Jun. 2017 


\section{O PROCESSO PENAL NA SOCIEDADE DE RISCO: A PERSECUÇÃO PENAL ENTRE OS IDEAIS DE LIBERDADE E SEGURANÇA}

quando a prova puder ser obtida por outros meios, a evidenciar que a execução da medida deve observar o princípio da proporcionalidade, bem como de que o agente que não observar a estrita finalidade da investigação, durante a execução das tarefas, será responsabilizado pelos excessos praticados. Todos os atos eletrônicos praticados durante a operação deverão ser registrados, gravados, armazenados e encaminhados ao juiz e ao Ministério Público, acompanhados de relatório circunstanciado, e deverão ser reunidos em autos apartados, assegurando-se a preservação da identidade do agente policial infiltrado e a intimidade das crianças e dos adolescentes envolvidos.

Como visto, a evolução legislativa destacada põe em evidência a tendência políticocriminal de busca por maior eficiência na prevenção e na repressão de específicos tipos de delitos que potencializam a sensação de insegurança no âmbito da sociedade, seja por criarem na atual conjuntura riscos até então inexistentes, decorrentes das novas tecnologias disponíveis, seja por potencializarem riscos já conhecidos, relacionados à criminalidade tradicional. Ao exame da legitimidade dessa tendência é dedicado o ponto que segue.

\section{A MATERIALIZAÇÃo dA SEGURANÇA PELA VIA PROCESSUAL PENAL: A PRETENDIDA EFICIÊNCIA PELA VIA DA PREVENÇÃO}

A legitimidade da expansão da intervenção estatal no âmbito penal e processual penal está diretamente relacionada, como visto na primeira parte deste ensaio, a uma obrigação de segurança atribuída ao Estado. Destarte, o exame crítico da evolução legislativa acima destacada pressupõe uma aproximação à vertente doutrinária que, amparada na dupla face dos direitos fundamentais, sustenta a existência de um dever objetivo de proteção dos mesmos, atribuído ao Estado.

Em um juízo retrospectivo, verifica-se que os Estados constitucionais surgem orientados à salvaguarda dos direitos individuais, como proteção dos cidadãos contra o abuso de poder que marcou o absolutismo até o Séc. XVII (FELDENS, 2012, p. 21/22). Com efeito, da teoria do contrato social que deu ensejo ao Estado absoluto hobbesiano, é possível identificar que o intuito da formação estatal era a proteção dos bens jurídicos mais básicos, como a vida, a propriedade e a liberdade, em face do risco decorrente de agressões perpetradas pelos próprios indivíduos. Tratava-se de restringir parcela de liberdade em prol de garantir a fruição da própria liberdade, através da segurança garantida pelo Estado, a quem eram atribuídos amplos poderes: “na sua formatação de Estado, este provê a paz através do monopólio da utilização da violência

Rev. de Direito Penal, Processo Penal e Constituição | e-ISSN: 2526-0200 | Brasília | v. 3 | n. 1 | p. 97 - 117 | Jan/Jun. 2017 
física legítima e retira dos cidadãos o direito e o poder de serem juízes e executores dos seus próprios assuntos.” (INSENSE, 2014, p. 17).

Daí até a formatação do Estado constitucional, a formatação estatal passou por diferentes estágios. Sem a pretensão de aprofundar a teoria constitucional, o que extrapolaria os limites do presente estudo, calha ressaltar a formatação do Estado de Direito, inicialmente com a doutrina de John Locke e depois com a teoria de Montesquieu, no qual a liberdade já não era mais assegurada pelo Estado, mas pela lei, através da qual se impunham limites ao poder do soberano. O risco à liberdade já não se restringia aos demais particulares; se materializava também na pessoa do soberano, cuja concentração de poderes era terreno fértil ao abuso. Com Locke surgiu a ideia de segurança frente ao guardião da segurança, e a compreensão de que ambos os valores poderiam coexistir (INSENSE, 2014, p. 23). Neste cenário, marcado pelo positivismo que dominou as revoluções americana e francesa, a tutela da liberdade era estabelecida pela autoridade da lei, pelo governo das leis, não dos homens. Sendo a pessoa o princípio e o fim do Estado, a sua liberdade se apresenta como condição de desenvolvimento mais básica. Por isso a liberdade era considerada ilimitada, como regra, sendo apenas passível de limitação pela lei. A função do Estado era velar pela segurança, através da certeza e estabilidade do Direito positivo (FELDENS, 2012, p. 22/23).

Foi, no entanto, na formatação política liberal que o fim do Estado restou reduzido ao ideal de segurança da liberdade contra os riscos exteriores e interiores. O Estado, na teoria liberal, não deveria ir além de assegurar essa liberdade, ou melhor, de assegurar as condições necessárias ao desenvolvimento da liberdade dos seus cidadãos. O Estado liberal se converte em guardião dos limites da liberdade, o que significa ser garante da segurança. Com isso se reduz o âmbito do Estado à segurança, e se amplia o âmbito das liberdades individuais (INSENSE, 2014, p. 26). É neste cenário que liberdade e segurança são compreendidas como duas faces da mesma moeda, a designar a ideia de integridade dos bens jurídicos fundamentais: a liberdade entre os cidadãos, a conformar uma relação horizontal, e a segurança entre cidadãos e Estado, a retratar uma relação vertical. Daí a concepção de um status positivus libertatis, a designar uma face objetiva dos direitos fundamentais, da qual decorre um dever de proteção imposto ao Estado.

Mas se o liberalismo era direcionado à realização da liberdade, a democracia é direcionada para a igualdade. Pautado no pressuposto de que o Estado é composto e se desenvolve através de pessoas que também estão sujeitas poder ao Estado, e que o povo é soberano enquanto sujeito deste poder, a segunda fase de formação dos Estados constitucionais

Rev. de Direito Penal, Processo Penal e Constituição | e-ISSN: 2526-0200 | Brasília | v. 3 | n. 1 | p. 97 - 117 | Jan/Jun. 2017 


\section{O PROCESSO PENAL NA SOCIEDADE DE RISCO: A PERSECUÇÃO PENAL ENTRE OS IDEAIS DE LIBERDADE E SEGURANÇA}

é pautada na busca pela autodeterminação política dos cidadãos, que deixam a condição de meros expectadores, para assumir o exercício do poder. Os cidadãos assumem o status de sujeitos de direito e os direitos fundamentais passam a ser tratados como "pressupostos do consenso a partir do qual se desenvolve uma sociedade democrática", a revelar, em essência, parcelas de liberdade "atreladas às diversas formas de exercício da cidadania", na medida em que contêm decisões fundamentais sobre a estrutura do Estado e a posição ocupada pela pessoa humana (FELDENS, 2012, p. 23/38).

A partir dessa construção teórica Feldens sustenta uma concepção objetiva dos direitos fundamentais, agora não mais restrito a um âmbito negativo de defesa em face do Estado, mas também positivo, a designar um imperativo de tutela desses próprios direitos, um dever de proteção que decorre da concepção destes como uma espécie de ordem objetiva de valores da sociedade (2012, p. 45 e seg.). É o que se denomina de proibição de proteção deficiente. Também nesta linha, Insense sustenta a existência de deveres constitucionais de proteção penal, mas destaca que tanto não se confunde com a eficácia horizontal dos direitos fundamentais, pois esta se resolve no âmbito privado, entre os particulares, enquanto os deveres de proteção ensejam relação de direito público entre o Estado e o titular de direitos fundamentais ameaçados (2010, p. 63).

Com base nessa concepção de deveres de proteção, entre nós, Baltazar Junior sustenta, especificamente em relação ao crime organizado, a obrigação da intervenção penal imposta ao Estado, tanto pela perspectiva material quanto processual penal. Segundo o autor, a sensação de insegurança gerada pelos novos riscos inerentes às ações dos grupos organizados legitima a intervenção penal, inclusive mediante a previsão legislativa de novos meios de investigação e obtenção de prova, sendo possível falar em um mandado explícito de criminalização decorrente da Convenção de Palermo (2010, p.211 e seg.). Tal afirmação decorre do reconhecimento de deveres objetivos de proteção impostos ao Estado, a partir da concepção de dupla face dos direitos fundamentais.

Em linha oposta, crítica ao que denomina de neoconstitucionalismo fundado em um autoritarismo cool, Gloeckner identifica nessa doutrina uma "tentativa de manutenção do discurso conservador hegemônico" (2012, p. 36), que em boa medida identifica o fenômeno da esquerda punitiva. No dizer do citado autor, a teoria neoconstitucional estruturada na proibição de proteção deficiente, ao ser transposta do âmbito cível para o criminal, reintroduz neste o superado conceito de lide penal e, consequentemente, de pretensão punitiva como direito 
subjetivo do Estado, que ao pressupor um direito à obediência ao Estado, afigura-se por excelência antidemocrático. Conforme Gloeckner, a dicotomia direito à segurança versus direito à liberdade retrata uma nova denominação da lide aplicada ao processo penal e enseja uma intervenção penal desprovida de legitimidade, de limitação e de efetividade, pois pautada em um supra bem jurídico (segurança), abstrato e intangível, "capaz de reunir em torno de si as mais diversas fontes de inspiração neocriminalizante ou redutora de garantias fundamentais" (2012, p. 39/44).

A crítica destacada encontra eco no saber criminológico enunciado por Alessandro Baratta, que diferencia o direito à segurança da segurança dos direitos, a sustentar que a segurança é uma necessidade secundária e acessória, que somente se justifica na medida em que instrumental a assegurar a efetividade de outros bens jurídicos de primeira grandeza, como é o caso da liberdade. "A segurança é uma necessidade humana e uma função geral do sistema jurídico", mas "em nenhum dos dois casos possui conteúdo próprio", afirma o autor, sustentando que um direito fundamental à segurança "não pode ser mais do que o resultado de uma construção constitucional falsa ou perversa" (2004, p. 199/200). Ademais, acrescenta Baratta, o sistema penal não é capaz de assegurar um direito fundamental à segurança, pois estruturado para intervir sobre os efeitos de um fato, e não sobre sua causa; porque atua sobre pessoas, e não sobre situações; porque atua de maneira reativa, e não preventiva; e porque moldado para tutelar a validade da norma, mais do que vítimas potenciais (2004, p. 161).

Delineados os pontos controvertidos acerca da legitimidade da expansão do controle penal fundada nos novos riscos e na insegurança deles decorrentes, e sem a pretensão de nos limites deste ensaio assumir posição para um lado ou para o outro, certo é que, a despeito da crítica destacada, a ampliação das zonas de intervenção penal, tanto pela via material quanto processual, encontra fundamento na doutrina constitucional que sustenta a existência de deveres objetivos de proteção impostos ao Estado. Ancorada na ideia de proibição de proteção deficiente, e excluídas as hipóteses em que o mandado de criminalização é explicitamente previsto na Constituição Federal, de um lado, e os casos em que a proibição de criminalização é também inequívoca, de outro, na zona intermediária, onde a tutela penal é possível (porque não vedada), a opção por esta via tem se mostrado mais intensa, tanto qualitativa quanto quantitativamente.

Efetivamente, como demonstrado no item anterior, a evolução legislativa nesses primeiros anos do Século XXI demonstra um incremento quantitativo inequívoco de leis ordinárias que tipificam novas metodologias de investigação e obtenção de prova. Tais 


\section{O PROCESSO PENAL NA SOCIEDADE DE RISCO: A PERSECUÇÃO PENAL ENTRE OS \\ IDEAIS DE LIBERDADE E SEGURANÇA}

diplomas legais, a toda evidência, flexibilizam garantias processuais ou implementam uma nova forma de atuação do Estado na investigação criminal, mais dinâmica e mais flexível, o que se verifica quando excepcionam a obrigatoriedade de atuação policial em caso de flagrante delito, por exemplo, ou quando estabelecem hipótese de não oferecimento da denúncia nos casos de colaboração premiada, excepcionando a obrigatoriedade da ação penal, ou ainda quando autoriza a prática de crimes pelo agente infiltrado. Em todos esses casos se identifica um incremento qualitativo em termos de intervenção penal, o que também se verifica na criação de obrigações de conversação de dados públicos e privados, assim como na permissão de acesso irrestrito a dados cadastrais, e também na possibilidade irrestrita de identificação criminal por perfil genético, sem qualquer referência à proporcionalidade como critério delimitador da intervenção penal.

Sob outro aspecto, agora no âmbito jurisdicional, da law in action, a flexibilização de garantias processuais inerente à expansão da intervenção penal é perceptível na medida em que a forma perde o seu conteúdo de garantia e passa a ser tratada como formalidade. Neste ponto a relativização das nulidades, inclusive as denominadas absolutas, é o termômetro que identifica uma tendência consolidada. O mesmo vale para a flexibilização da inadmissibilidade constitucional das provas ilícitas e para a ampliação irrestrita dos poderes instrutórios do juiz, inclusive na fase pré-processual, dentre outros aspectos que mereceriam estudo específico, como é o caso da consolidação do entendimento jurisprudencial que restringe o âmbito de eficácia do habeas corpus.

Em ambos os planos, enfim, transparece nítido o intuito de assegurar maior eficiência à intervenção penal através da sua antecipação e da sua flexibilização, como forma de prevenir a realização dos riscos e, assim, concretizar a segurança da sociedade.

\section{CONSIDERAÇÕES FINAIS}

A título de fechamento, e sem a pretensão de esgotar o enfrentamento do tema, é possível afirmar que a expansão do controle penal, tanto pela via material quanto pela via processual, encontro fundamento nos riscos inerentes à complexidade da sociedade globalizada. Seja pelo surgimento de novos riscos antes imperceptíveis, seja pela potencialização de riscos já conhecidos, o recurso à tutela penal por parte do Estado tem se ocupado neste novo milênio como uma posição de destaque na política criminal.

Rev. de Direito Penal, Processo Penal e Constituição | e-ISSN: 2526-0200 | Brasília | v. 3 | n. 1 | p. 97 - 117 | Jan/Jun. 2017 
No âmbito do ordenamento jurídico brasileiro, este cenário pode ser constatado sem dificuldades pela análise da evolução legislativa em matéria de persecução penal, notadamente pelo incremento quantitativo e qualitativo que se observa na última década, em especial o verificado entre os anos de 2012 e 2013. Sob outro aspecto, também no plano jurisdicional esta tendência é perceptível, por exemplo, pela ampliação de poderes instrutórios do juiz, pela flexibilização da inadmissibilidade constitucional das provas ilícitas, e pela ausência de efetividade da Lei 12.403/11, que estabeleceu medidas alternativas à prisão, o que, somado ao elevado número de presos preventivos no Brasil, indica o possível uso da custódia cautelar como instrumento de antecipação da intervenção punitiva estatal.

Este cenário, consoante se tentou demonstrar, encontra fundamento na teoria constitucional que, pautada na dimensão objetiva dos direitos fundamentais, sustenta a existência de deveres objetivos de proteção impostos ao Estado, dentre eles um dever de garantir a segurança pública, inclusive pela via penal. Neste ponto, a controvérsia se limita à legitimidade da tutela penal, e não propriamente à existência de deveres objetivos de proteção dos direitos fundamentais, impostos ao Estado. Assim porque não paira dúvida quanto à dimensão objetiva dos mesmos, e também quanto ao fato de que, em um Estado democrático, a realização dos direitos fundamentais depende de que o Estado implemente medidas a assegurá-los. Se a tutela penal é necessária e adequada a essa implementação, esse é o ponto que merece atenção e exige reflexão. A realidade, porém, está a evidenciar o recorrente recurso do Estado ao controle penal.

\section{REFERÊNCIAS}

BALTAZAR JUNIOR, José Paulo. Crime organizado e proibição de insuficiência. Livraria do Advogado: Porto Alegre, 2010.

BARATTA, Alessandro. Seguridad. In: Criminologia y sistema penal (compilación in memoriam). Editorial B e F: Buenos Aires, 2004, p. 199-220.

BECK, Ulrick. La sociedade del riesgo. Hacia una nueva modernidade. Paidós: Barcelona, 1998;

CAMPIONE, Roger. El que algo quiere algo le cuesta: notas sobre la kollateralschädengesellschaft. In: DE AGRA, Cândido; DOMÍNGUEZ, José Luis; GARCIA AMADO, Juan Antonio; HEBBERECHT, Patrick; RECAENS, Amadeu [Orgs.]. La seguridad en la sociedad del riesgo. Un debate abierto. p. 11-26. Atelier: Barcelona, 2003. 


\section{O PROCESSO PENAL NA SOCIEDADE DE RISCO: A PERSECUÇÃO PENAL ENTRE OS \\ IDEAIS DE LIBERDADE E SEGURANÇA}

D'ÁVILA, Fábio Roberto. Liberdade e segurança em Direito Penal. O problema da expansão da intervenção penal. In: POZZEBON, Fabrício Dreyer de Ávila; ÁVILA, Gustavo Noronha de. Crime e interdisciplinariedade. Porto Alegre: ediPUCRS, 2012, pp. 273-286.

DIEZ RIPOLLÉS, José Luis. De la sociedad del riesgo a la seguridad ciudadana: un debate desenfocado. Revista electrónica de ciência penal y criminologia. n. ${ }^{\circ}$ 07, jan/2005, p. 01-37.

FARIA COSTA, José de. Direito Penal e globalização: reflexões não locais e pouco globais. Coimbra editora: Coimbra, 2010.

FELDENS, Luciano. Direitos Fundamentais e Direito Penal - A Constituição Penal. 2.ed. Livraria do Advogado: Porto Alegre, 2012.

GIDDENS, Anthony. As consequências da modernidade. São Paulo: Unesp, 1991.

GLOECKNER, Ricardo Jacobsen. Risco e processo Penal. JusPodium: Salvador, 2009.

Alguns perigos do constitucionalismo contemporâneo no Processo Penal. Revista Síntese de Direito Penal e Processo Penal, v. 13, nº 75, Porto Alegre, Ago.-Set./2012, p. 3453.

INSENSE, Josef. El derecho constitucional a la seguridade. Santa Fe: Rubinzal-Culzoni, 2014.

LUHMANN, Niklas. Sociología del Riesgo. México: Universidade Iberoamericana, 2006; BAUMAN, Zygmunt. Modernidade e Ambivalência. Rio de Janeiro: Jorge Zahar Editor, 1999.

PÉREZ CEPEDA, Ana Isabel. La seguridad como fundamento de la deriva del derecho penal postmoderno. Iustel: Madrid, 2007.

SILVA SÁNCHEZ, Jesús María. La expansión del derecho penal. Aspectos de la Política Criminal en las sociedades postindustriales. ${ }^{a}$. Ed. Montevideo-Buenos Aires: B de f, 2006.

Rev. de Direito Penal, Processo Penal e Constituição | e-ISSN: 2526-0200 | Brasília | v. 3 | n. 1 | p. 97 - 117 | Jan/Jun. 2017 